\title{
Electrospun nylon-6 nanofibers and their characteristics
}

\author{
Ida Sriyanti ${ }^{1,2 *}$, Meily P Agustini ${ }^{3}$, Jaidan Jauhari ${ }^{4}$, Sukemi $^{5}$ and Zainuddin Nawawi ${ }^{6,7}$ \\ ${ }^{1,3}$ Physics Education, Faculty of Education, Universitas Sriwijaya, Palembang, South Sumatera, Indonesia \\ $2,4,5,6$ Laboratory of Instrumentation and Nanotechnology Applications, Faculty of Computer Science, \\ Universitas Sriwijaya, Palembang, South Sumatera, Indonesia \\ ${ }^{7}$ Department of Electrical Engineering, Universitas Sriwijaya, Palembang, South Sumatera, Indonesia
}

*Corresponding Address: ida_sriyanti@unsri.ac.id

\begin{tabular}{|c|c|}
\hline Article Info & ABSTRACT \\
\hline Article history: & \multirow{5}{*}{$\begin{array}{l}\text { The purposes of this research were to investigate the synthesized Nylon- } 6 \\
\text { nanofibers using electrospinning technique and their characteristics. The } \\
\text { method used in this study was an experimental method with a quantitative } \\
\text { approach. Nylon- } 6 \text { nanofibers have been produced using the electrospinning } \\
\text { method. This fiber was made with different concentrations, i.e. } 20 \% \mathrm{w} / \mathrm{w} \\
\text { (FN1), } 25 \% \mathrm{w} / \mathrm{w} \text { (FN2), and } 30 \% \mathrm{w} / \mathrm{w} \text { (FN3). The SEM results show that the } \\
\text { morphology of all nylon- } 6 \text { nanofibers) forms perfect fibers without bead fiber. } \\
\text { Increasing fiber concentration from } 20 \% \mathrm{w} / \mathrm{w} \text { to } 30 \% \mathrm{w} / \mathrm{w} \text { results in bigger } \\
\text { morphology and fiber diameter. The dimensions of the FN1, FN2, and FN3 } \\
\text { fibers are } 1890 \mathrm{~nm}, 2350 \mathrm{~nm} \text {, and } 2420 \mathrm{~nm} \text {, respectively. The results of FTIR } \\
\text { analysis showed that the increase in the concentration of nylon- } 6 \text { (b) and the } \\
\text { electrospinning process caused a peak shift in the amide II group }\left(\mathrm{CH}_{2} \text { bond), }\right. \\
\text { the carbonyl group and the } \mathrm{CH}_{2} \text { stretching of the amide III group from small } \\
\text { wave numbers to larger ones. The results of XRD characterization showed } \\
\text { that the electrospinning process affected the changes in the XRD pattern of } \\
\text { nylon- } 6 \text { nanofiber (FN1, FN2, and FN3) in the state of semi crystal. Nylon- } 6 \\
\text { nanofibers can be used for applications in medicine, air filters, and electrode } \\
\text { for capacitors. }\end{array}$} \\
\hline $\begin{array}{l}\text { Received: January } 13^{\text {th }}, 2020 \\
\text { Accepted: March } 31^{\text {th }}, 2020 \\
\text { Published: April } 30^{\text {th }}, 2020\end{array}$ & \\
\hline Keywords: & \\
\hline & \\
\hline Nanofiber. & \\
\hline
\end{tabular}

(c) 2020 Physics Education Department, UIN Raden Intan Lampung, Indonesia.

\section{INTRODUCTION}

The development of nanotechnology is currently growing rapidly, one of which is nanofiber technology. Several methods for producing nanofibers are Drawin, template synthesis, phase separation, self-assembly, and electrospinning (Almetwally et al., 2017; Sriyanti et al., 2018). The Electrospinning method is one of several methods of making a nanometer to micrometers-sized polymer fibers (Shi et al., 2015; Edikresnhaet al., 2019). This is a simple and inexpensive method to produce nanofibers. To produce nanofibers, physics principles are used in the electrospinning method, which is by utilizing the Coulomb force due to free charge or ions on the surface of a polymer solution, so that when subjected to potential differences or very high voltage, this charged polymer solution can be attracted to the collector and forming polymer fibers (Pillay et al., 2013; Sriyanti et al., 2018). The morphology and size of the fibers produced can be adjusted by changing the parameters of the device, such as electrical voltage, needle tip distance with the collector, needle shape, polymer solution flow rate, and collector geometry, or by changing the polymer solution parameters, including conductivity, viscosity, and voltage surface (Matabola\& Moutloali, 2013; Sriyanti et al., 2016; Sriyanti et al., 2017). The electrospinning method is also a simple, 
easy, and inexpensive technique for producing nanofibers (Suwantong \& Pankongadisak, 2014). The Nanofiber membranes can be applied to drug-carrying systems (Sriyanti et al., 2017), wound dressing (Aruan et al., 2017; Dai et al., 2012), cosmetics (Opanasopit et al., 2011; Samprasit et al., 2015), and capacitors (Gao et al., 2013; Ismar et al., 2018).

Many polymers can be used as carrier matrix in the electrospinning technique. In this study, we use nylon-6 to produce nanofibers. Nylon-6 was chosen because it is easily spun (electrospinning), and can dissolve in polar and nonpolar solvents (An et al., 2017; Kang et al., 2012). Nylon-6 nanofiber membranes have been widely used as aerosol filtration media and filters because they can produce uniform fibers, have good mechanical properties, low density, and high porosity (Parlay et al., 2019). In the dry state, nylon-6 is shaped like a bead, while in the form of a solution, it thickens. If exposed to water, the nylon- 6 solution will be shaped like thick plastic. Several studies related to nylon-6 nanofiber are nylon-6/graphene for the removal of $\mathrm{Cr}$ (VI) adsorption (Parlay et al., 2019) and preparation of multi-layer nylon-6 nanofibers (Yu, 2018). However, Nylon-6 nanofibers produced using the electrospinning method with different concentrations and analysis of nanofibers characteristics (morphology, X-Ray Diffraction (XRD) and Fourier transform of the infrared spectrophotometer (FTIR) are found rarely.

In this study, the researchers synthesized Nylon-6 nanofibers using electrospinning technique and characterized the Nylon-6 nanofiber. The morphology and structure of the NF1, NF2, and NF3 nanofibers were analyzed by scanning electron microscope (SEM), XRD, and FT-IRof the nanofibers were investigated. The effect of increased PAN concentrations of nanofibers on morphology, structural changes, and molecular interactions of nanofibers was evaluated. The membrane of nylon- 6 nanofibers can be used for applications in wound dressing, air filters, and electrode for capacitors.

\section{METHODS}

The method used in this study was an experimental method with a quantitative approach. The electrospun of nylon- 6 nanofibers at the Laboratory of Instrumentation and Nanotechnology Applications, Faculty of Computer Science, Universitas Sriwijaya. The characterization of Scanning Electron Microscope (SEM), the Fourier-Transform Infrared (FTIR), and the X-ray Diffractometer (XRD) from nylon-6 nanofibers at Faculty of Mathematics and Natural Sciences (FMIPA), Universitas Sriwijaya.The Research duration of six months.

\section{Material}

The material used to produce the nylon- 6 membrane was one that has a density of $1,084 \mathrm{~g} / \mathrm{ml}$ and a melting point of $229.5^{\circ} \mathrm{C}$ obtained from Sigma-Aldrich. The solvent used was formic acid obtained from Bratachem, Indonesia.

\section{Preparation of Nylon-6 Solution}

The nylon- 6 precursor solution was made with various variations of polymer concentrations, i.e. $20 \% \mathrm{w} / \mathrm{w}$ (FN1), $25 \%$ w/w (FN2) and 30\% w/w (FN3). To prepare the solution, nylon- 6 polymer and formic acid solvent were weighed according to the variation of each concentration. The nylon- 6 precursor solution is stirred with a magnetic stirrer with a rotational speed of $500 \mathrm{rpm}$ for 4 hours at room temperature so that a homogeneous solution is obtained. The homogeneous nylon-6 solution was injected into a $10 \mathrm{ml}$ Terumo ${ }^{\circledR}$ injector with a diameter of $15 \mathrm{~mm}$, needle length of $38 \mathrm{~mm}$, and a needle diameter of $0.8 \mathrm{~mm}$. 


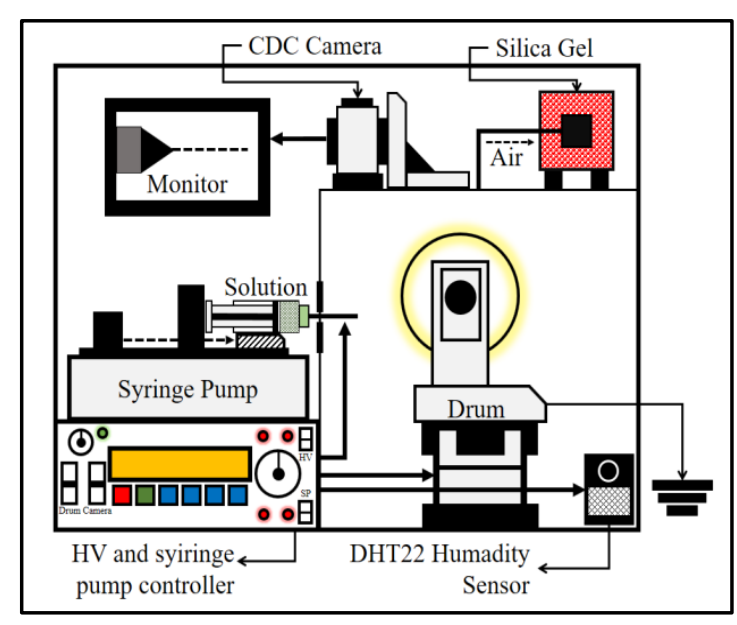

Figure 1.The Illustration of Electrospinning Process in the ExperimentsNylon-6 (Jauhari et a, 2019)

The illustration of the electrospinning process in this study is shown in Figure 1. Nylon-6 fiber was produced using an electrospinning machine named Nacriebe 601 Electrospinning. The electrospinning process optimum parameters used to produce Nylon-6 fibers are as follows: the voltage is $17 \mathrm{kV}$, the flowrate is $15 \mu \mathrm{L} /$ hour, and the distance of the tip of the needle to the collector is $10 \mathrm{~cm}$. During the spinning process, the collecting drum rotates and is positioned at a distance of $10 \mathrm{~cm}$ in front of the tip of the needle. The temperature and humidity of the electric spinner are constantly set at $25^{\circ} \mathrm{C}$ and $40-50 \%$. The collector drum used to collect fibers is given a cloth base, and aluminum foil sized $18 \mathrm{~cm}$ $\mathrm{x} 11 \mathrm{~cm}$. The details of variations in the nylon- 6 concentration are shown in Table 1 .

Table 1.Variations in the Concentration of Nylon-6

\begin{tabular}{ccc}
\hline No & Sample & Concentration \\
\hline 1 & FN1 & $20 \% \mathrm{w} / \mathrm{w}$ \\
2 & FN2 & $25 \% \mathrm{w} / \mathrm{w}$ \\
3 & FN3 & $30 \% \mathrm{w} / \mathrm{w}$ \\
\hline
\end{tabular}

\section{Characterization of Nylon-6 Nanofiber Membranes}

Observations with a Scanning Electron Microscope (SEM) were carried out to study the surface structure and morphology of materials. SEM is an electron microscope that has higher magnification compared to the optical microscope. The advantage of SEM lies in the ease of sample preparation as well as on the various signals produced by the interaction between the electron beam and the sample. The detection and processing of these various signals result in a variety of data views from the surface of the layer. The results of the reflection patterns in this process provide information in the form of topology and morphology on the surface of the sample. Each fiber (FN1, FN2, and FN3 (synthesized by the electric spinner was characterized using SEM JEOL type JSM6510LV in Palembang Regional Police. The picture is taken at 1000 times magnification with a voltage of $15 \mathrm{kV}$. The images obtained from the SEM characterization results were analyzed using image processing software (Image MIF v.3.0). The normal log distribution is used to further analyze fiber size and fiber size distribution.

\section{FTIR (Fourier Transform InfraRed)}

Fourier Transform InfraRed spectroscopy (FTIR) is a spectroscopy technique that can effectively provide information about the chemical composition of materials at the molecular level. FTIR is used to determine the chemical functional groups of organic and inorganic compounds (Bunaciu et al., 2015). In this study, FTIR is used to recognize the absorption peaks that correspond to the vibrational frequencies between the bonding of atoms in a nylon- 6 composite fiber. Measurements were made at the Faculty of Mathematics and Science of Universitas Sriwijaya at room temperature using Bruker Alpha type A220/D-01 FTIR spectrometer, which can collect spectral data in the spectrum range of $500-4000 \mathrm{w} / \mathrm{w}^{-1}$ with a resolution of $4 \mathrm{w} / \mathrm{w}^{-1}$.

\section{X-Ray Diffraction (XRD)}

XRD analysis is used to determine the morphology of the crystal and changes in crystal structure when it is made into nanofiber using the electrospinning method. The tool used is the PXRD Bruker D8 Advance. Samples were analyzed with $\mathrm{Cu} \mathrm{K}_{\alpha}$ 
and $\mathrm{K}_{\beta}$ radiation at $2 \theta$ with a range of $5^{\circ}$ to $60^{\circ}$. The analysis was carried out with a generator of $40 \mathrm{kV}$ and $35 \mathrm{~mA}$.

\section{RESULTS AND DISCUSSION Nylon-6 Nanofibers IMAGE}

The process of making nylon- 6 nanofibers using the electrospinning method with a rotating collector is shown in Figure 2. The device consists of: (1) Syringes in which a nylon-6 solution is to be spun. The syringe is placed in a pump that will push the solution out of the needle. (2) A high voltage source connected to the syringe. (3) Rotating collector to gather the fiber. In the electrospinning process (electric spinning), the charge will be induced into the solution when the needle is connected to a high voltage source. On the surface of the solution at the tip of the needle, ions or similar free charges that undergo repulsive electrostatic force will accumulate. Also, these free ions or charges undergo an electric force due to the influence of the electric field between the needle and the collector. When the resultant of these two types of forces exceeds the forces that arise due to the interaction of intermolecular polymers with solvents, a Taylor Cone will appear, then the polymer solution will be attracted to the drum collector (Jauhari et al., 2019; Kamaruddin et al., 2018). An external electric field is used to control the jet load coming out of the needle. The magnitude of the electric force is $\mathrm{F}_{\mathrm{E}}=$ ${ }_{\mathrm{Q}} \mathrm{E}$, where $\mathrm{q}$ is the electric charge $(\mathrm{C})$, and $\mathrm{E}$ is the electric field strength $(\mathrm{N} / \mathrm{C})$. The interaction force between the two charges $\mathrm{q}_{1}$ and $\mathrm{q}_{2}$ is known as Coulomb's Law, which is given by:

$$
F=k \frac{q_{1} q_{2}}{r^{2}}
$$

where $\mathrm{k}$ is a constant, and $\mathrm{r}$ is the distance of the two charges. The Taylor cone of nylon- 6 can be seen in Figure 2.

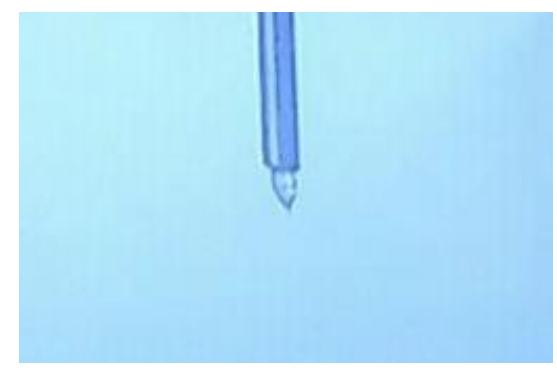

Figure 2.The Taylor Cone of Nylon-6 Solution

The final process on the way to the collector, the solvent molecule evaporates, the solution changes its form into solids and, at the same time, elongates, then collects on the surface of the collector forming fibers (Ramakrishna, 2005). Nylon-6 fibers with varying concentrations of $20 \% \mathrm{w} / \mathrm{w}$ (FN1), $25 \% \mathrm{w} / \mathrm{w}$ (FN2), and $30 \% \mathrm{w} / \mathrm{w}$ (FN3) collected in a rotating collector can be seen in Figure 3. Macroscopically, FN1, FN2, and FN3 fibers are visibly white with a smooth surface. The effect of the balance of the electrospinning process parameters and the nylon-6 solution with three variations of concentrations $(20 \% \mathrm{w} / \mathrm{w}, 25 \% \mathrm{w} / \mathrm{w}$, and $30 \% \mathrm{w} / \mathrm{w}$ ) produce the perfect nylon-6 fiber. The results of this study are consistent with previous studies in which the balance of electrospinning parameters and PVP/CA solutions produces perfect and smooth fibers (Jauhari et al., 2019). 

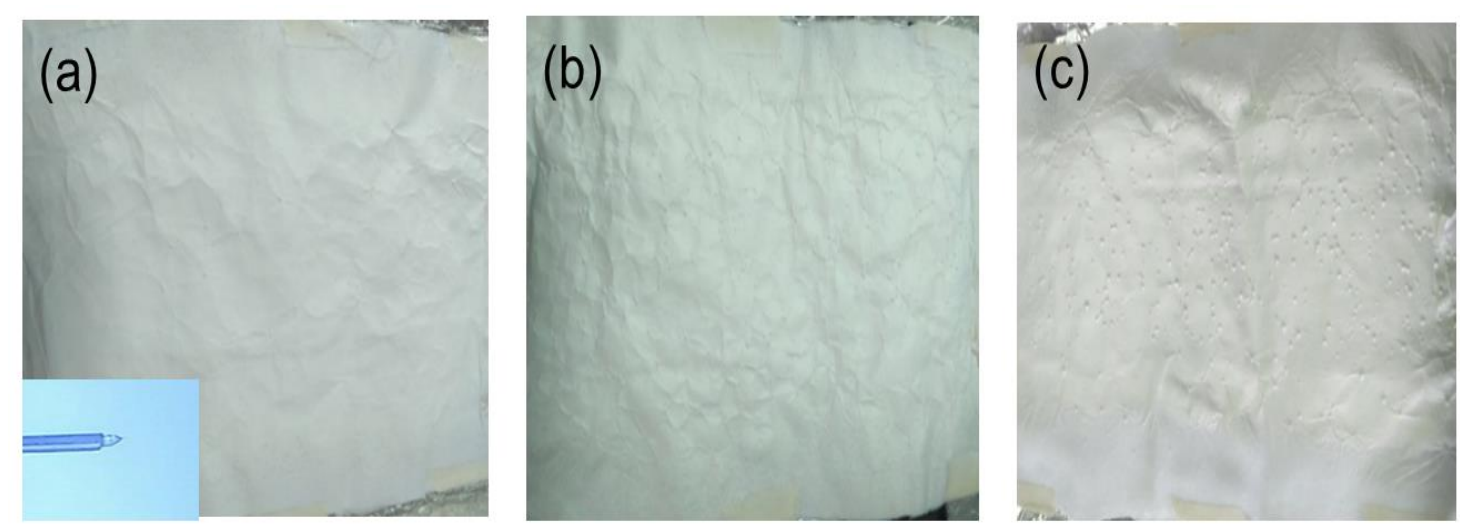

Figure 3. Nylon-6 Nanofibers Image: (a) FN1 Nanofiber, (b) FN2 Nanofiber, and (c) FN3 Nanofiber

\section{Morphology and Size Distribution of Nylon-6 Nanofibers}

Figure 4 shows the morphology and size distribution of FN1, FN2, and FN3 nanofibers obtained using SEM with 1000 times magnification. The variations of Nylon-6 concentration used in this study were $20 \%$ (w/w) (FN1), 25\% (w/w) (FN2), and $30 \%(\mathrm{w} / \mathrm{w})(\mathrm{FN} 3)$. The parameters of the electrospinning process used in this study are as follows: the magnitude of the voltage is 17 $\mathrm{kV}$, the flow rate is $1 \mathrm{~mL} / \mathrm{hr}$, the distance between the tip of the needle to the collector is $10 \mathrm{~cm}$ and the outer diameter of the needle is $0.8 \mathrm{~mm}$. The SEM image results in Figure 4 (a-c) show the FN1, FN2, and FN3 nanofibers in the form of strands like regular hair and free-bead fiber. The regular hair fiber can be used for air filter applications (Yuxi et al., 2018). There is no bead fiber in nylon-6 fiber due to the influence of the solution balance and the electrospinning process parameter. The bead fiber will form in case of the lower viscosity of the solution and the presence of other materials in it. Solutions with low polymer concentration have few polymer chain bonds so that the beam is not continuous (intermittent) during spinning (Sriyanti et al, 2017) which can cause the formation of beads on the fibers. However, in this study, the viscosity of the nylon-6 solution was higher so that the resulting nylon- 6 polymer chain could be pulled by the electrostatic force to produce perfect or free-bead fiber. At this point, the polymer chains have fully been extended and the inertial force of beaded form is more dominant than the viscous force, which causes resistance to form fiber (Sriyanti et al., 2017; Clasen et al., 2009; Jauhari et al., 2019) This research is similar to that carried out by (Jauhari et al., 2019; Sriyanti et al., 2017), where the effect of the polymer chain balance (solution construction) produces free-bead fiber (Jauhari et al., 2019). Also, the absence of other polymer mixtures in the nylon- 6 solution produces perfect and freebead fiber. 

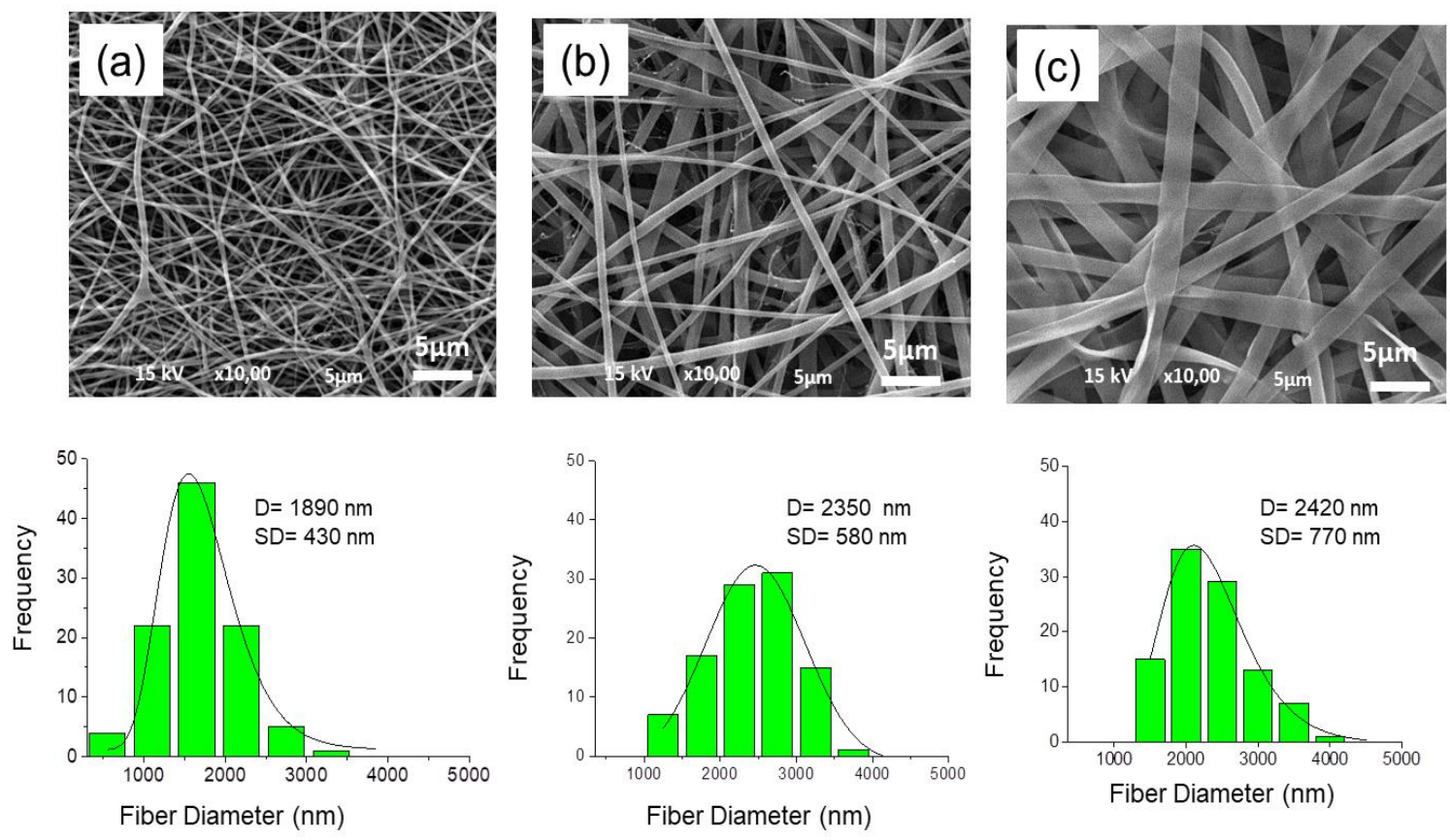

Figure 4. SEM Images and Diameter Distributions of (a) FN1, (b) FN2 and (c) FN3 Nanofibers

The size distribution of nylon- 6 fibers with variations in polymer concentration obtained (FN1, FN2, and FN3) is shown in Figure 4 (a) -4 (c). For nanofiber FN1 (20\% of weight), the diameter is distributed from 800 to 3800 $\mathrm{nm}$ with an average diameter $(D)$ of $1890 \mathrm{~nm}$ and a standard deviation (SD) of $430 \mathrm{~nm}$. The rage diameters (D), diameters and standard deviations (SD) of FN2 nanofibers $(25 \% \mathrm{w} / \mathrm{w})$ are 1000-4000 nm, $2350 \mathrm{~nm}$, and $580 \mathrm{~nm}$, respectively. The range, fiber diameter, and SD for FN3 nanofiber $(30 \% \mathrm{~b} / \mathrm{b})$ are 1200 $4200 \mathrm{~nm}, 2420 \mathrm{~nm}$, and $770 \mathrm{~nm}$, respectively. Increasing the concentration of polymer can increase the size of the diameter of the fiber. Fiber diameter has increased from $1890 \mathrm{~nm}$ for fibers with a polymer concentration of $20 \%(\mathrm{w} / \mathrm{w})(\mathrm{FN} 1)$ to $2420 \mathrm{~nm}$ for fibers with a polymer concentration of $30 \%(\mathrm{w} / \mathrm{w})(\mathrm{FN} 3)$. That is because the higher the concentration of the polymer will increase the chain of polymer chains in the solution so that more polymers can be spun (Shenoy et al., 2005; Vongsetskul et al., 2015). Also, an increase in the concentration of the polymer (which means less amount of the solvent) causes the solvent to dry faster so that less time is needed by the Columb force to stretch the fiber to produce a larger fiber diameter. This finding is similar to recently reported research for $\mathrm{PVP} / \mathrm{CA}$ (Jauhari et al., 2019), PVP/GME (Sriyanti et al., 2018; 2017), and PVP/curcumin (Samprasit et al., 2015).

The coefficient of variance $(\mathrm{CV})$ is standard. A distribution is homogeneous if it has a standard deviation ratio with an average fiber diameter of less than 0.3 (Matulevicius et al., 2016). In this research, the diameter of Nanofiber FN1, FN2, and FN3 was 0.26, 0.28, and 0.27 , respectively. The results of this $\mathrm{CV}$ indicate that the distribution of FN1, FN2, and FN3 fibers is homogeneous. High voltage does not affect the jet balance or does not produce a lot of side jets so that the fiber diameter is homogeneous.

\section{Characteristics of Nanofiber through the Fourier-Transform Infrared (FTIR) Process}

The nanofibers that have been produced are then characterized through the FourierTransform Infrared (FTIR) process. The purpose of the FTRI test is to identify functional groups, and the peak is shown in Figure 5. The peak in the wave range between $3000-3600 \mathrm{~cm}^{-1}$ shows the sharp peak at wave number $3303 \mathrm{~cm}^{-1}(\mathrm{FN} 1), 3305 \mathrm{~cm}^{-1}$ 
(FN2) and $3317 \mathrm{~cm}^{-1}$ (FN3) which is an amide group including stretching the $\mathrm{NH}$ bond $(\mathrm{NH}$ stretching)(Kang et al., 2012). Other peaks appear at wavenumbers 2942, $964 \mathrm{~cm}^{-1}$ (FN1), 2944,893 $\mathrm{cm}^{-1}$ (FN2), dan 2950,678 $\mathrm{cm}^{-1}$ (FN3) which was identified as stretching the $\mathrm{CH}_{2}$ bonds of the amide II group (Kang et al., 2012). The presence of stretching of $\mathrm{C}=\mathrm{O}$ bond (carbonyl group) is shown for samples FN1, FN2, and FN3, which can be seen from sharp peaks at wavenumber $1637,337 \mathrm{~cm}^{-1}$, 1639,266 $\mathrm{cm}^{-1}$, dan 1645,052 $\mathrm{cm}^{-1}$, respectively. The next peaks that appear at wave numbers 1268 (FN1), 1268 (FN2) and 1269 (FN3) are identified as $\mathrm{CH}_{2}$ stretching of the amide III group, whereas in FN1, FN2 and FN3 the peak is at the wave number 1465, 697 $\mathrm{cm}^{-1}, 1465,697 \mathrm{~cm}^{-1}$ and 1490,768 $\mathrm{cm}^{-1}$ respectively. The peaks identify the $\mathrm{CH}$ bond (Kang et al., 2012; Parlay et al., 2019).

The influence of the electrospinning process and the increase in the concentration of nylon-6 polymers (in weight) causes a shift in the peak in the amide group, including stretching the $\mathrm{N}-\mathrm{H}$ bond (N-H stretching) to a higher wavenumber. Wave magnification also occurs in the amide II group $\left(\mathrm{CH}_{2}\right.$ bond), the carbonyl group, and the $\mathrm{CH}_{2}$ stretching of the amide III group from smaller wave numbers become larger. The displacement of the carbonyl stretching peak and other peaks are considered as a result of interactions between the Nylon molecules caused by the electric spinning process. In addition to the electrospinning process, the higher formic acid content causes the amide peak to be sharper and more visible to occur around 3000 $-3600 \mathrm{~cm}^{-1}$.

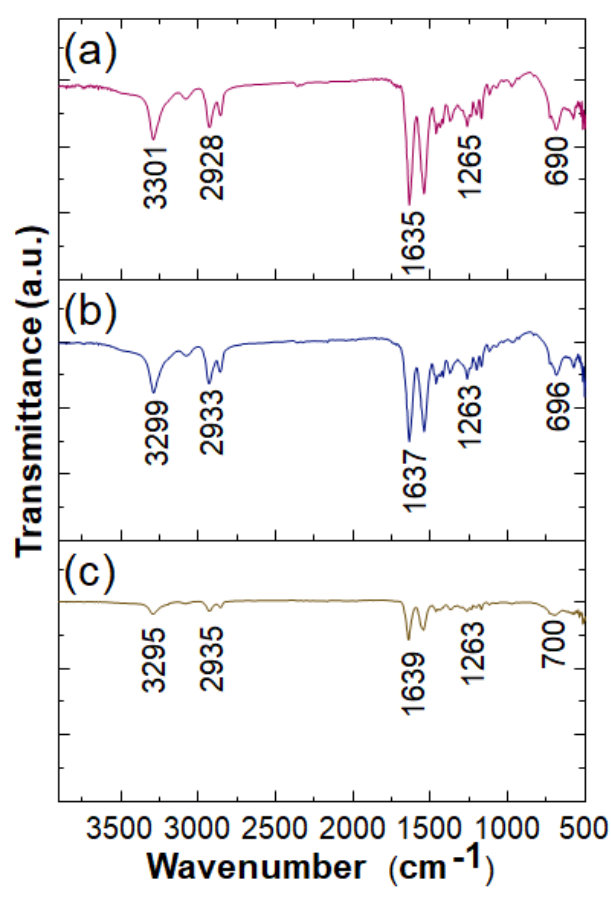

Figure 5. FTIR spectra of (a) FN1 Nanofiber, (b) FN2 Nanofiber, and FN3 Nanofiber

\section{XRD Characterization of Nylon -6 Nanofiber}

Characterization of $\mathrm{X}$-ray diffraction is used to see the interaction of Nylon-6 molecules and solvents by looking at changes in crystallinity that occur. The pattern of XRD analysis results from nanofiber FN1, FN2, and FN3 are presented in Figure 6. The nanofiber FN1 diffraction pattern has two sharp peaks at an angle of $2 \theta$, namely $16.76^{\circ}$, and $24.32^{\circ}$, while the other pattern shows a broad halo pattern. The diffraction pattern of $\mathrm{FN} 2$ 
nanofiber has four sharp peaks at an angle of $2 \theta$, namely the first peak of $14^{\circ}$, the second peak of $16.9^{\circ}$, the third peak of $18.1^{\circ}$ and the fourth peak of $21.2^{\circ}$. While the diffraction pattern on FN3 nanofiber has four sharp edges at position $2 \theta$, namely $16^{\circ}, 20.9^{\circ}$, and $24.6^{\circ}$. These peaks indicate that the nylon- 6 molecular diffraction pattern is a semi crystal pattern (Mehran \& Mojtaba, 2011).

According to Kayaci (2012), the pure nylon-6 XRD pattern is Crystal (Kayaci et al., 2012). However, in this study, the nylon-6 XRD nanofiber pattern became semi crystal. These observations show that nylon- 6 is no longer present as a crystalline pattern but turns into semi crystal. This change in the structure of nylon- 6 may have been caused by the spinning process.

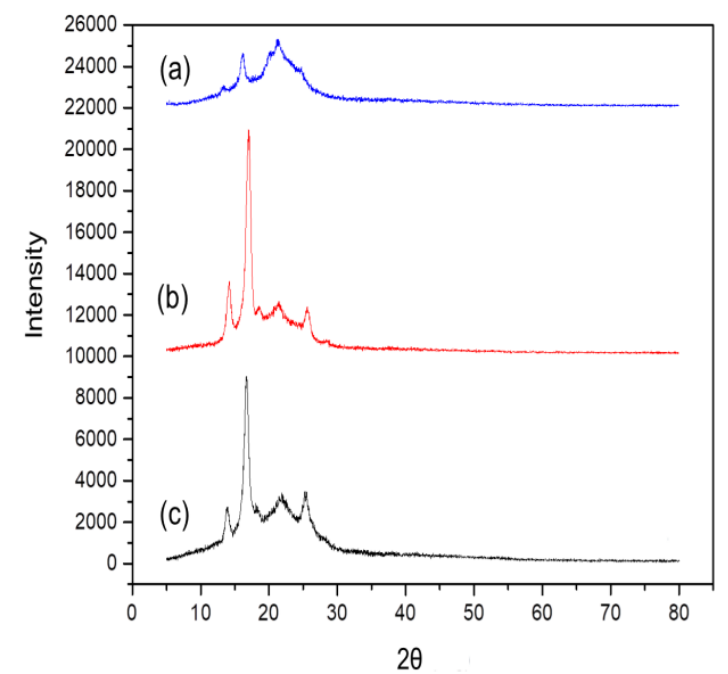

Figure 6.X-ray diffraction of (a) FN1 nanofiber, (b) FN2 nanofiber, and (c) FN3 Nanofiber

The main reason for this finding is amorphization during the electric spinning process. When the precursor solution is attracted to the collector and is stretched out, the liquid changes into a solid. During the process of transformation, the solvent molecules evaporate, while the polymer molecules remain bonded to each other, but the bonds become stronger. This process is influenced by ionic motion, which is accelerated by an electric field and takes place so fast that the nylon- 6 molecules do not have time to be oriented in such a way as to form a crystal structure. (Sriyanti et al., 2017; 2018;
Jauhari et al., 2019). The same thing has also been reported by Dai (2012) in the spinning of PVP/Emodin in which the influence of the electrospinning process has resulted in emodin XRD diffraction patterns, which initially had crystalline patterns become amorphous or semi crystal patterns (Dai et al., 2012).

\section{CONCLUSION AND SUGGESTION}

Nylon-6 nanofiber has been successfully made with three variations of construction, namely $20 \% \mathrm{w} / \mathrm{w}$ (FN1), 25\% w/w (FN2), and $30 \% \mathrm{w} / \mathrm{w}$ (FN3) using the electrospinning method. To produce nylon-6 nanofiber, three forces influence the process, namely Columb force, surface tension force, and thrust force. Macroscopically, the result can be seen in the form of a white nanofiber of FN1, FN2, and FN3 with a smooth surface. The SEM image results show the FN1, FN2, and FN3 nanofibers are in the form of regular hair strands and free-bead fibers. There is no bead in the fiber due to the influence of the nylon- 6 solution balance and the electrospinning process parameters. Increasing the concentration of polymer (weight/weight) can increase the size of the fiber diameter. The diameters of FN1 nylon fibers $(20 \% \mathrm{w} / \mathrm{w})$, $\mathrm{FN} 2(25 \% \mathrm{w} / \mathrm{w})$ and $\mathrm{FN} 3(30 \% \mathrm{w} / \mathrm{w})$ were 1880, 2210 and $2400 \mathrm{~nm}$, respectively. The influence of the electrospinning process and the increase in the concentration of nylon- 6 polymers (in weight) cause a shift in the peak in the amide group, including $\mathrm{N}-\mathrm{H}$ stretching to a higher wavenumber. Wavenumber enlargement also occurs in the amide II group ( $\mathrm{CH}_{2}$ bond), the carbonyl group and the $\mathrm{CH}_{2}$ stretching of the amide III group from smaller wave numbers become larger. The effect of the electrospinning process resulted in the XRD nylon-6 diffraction pattern (FN1, FN2, and non-fibrous FN3) changed to a semi crystal pattern.

\section{Acknowledgments}

This research was financially supported by Universitas Sriwijaya, Republik of Indonesia, under the University's Excellence Research 
(PUPT) Grant in the fiscal year of 2020. This research was financially supported by BPDPKS, Republik of Indonesia, under the Research and Development of Palm Oil in the fiscal year 2020 .

\section{AUTHOR CONTRIBUTIONS}

IS conceptualization and criticisms. MP and $\mathrm{ZN}$ reviewing literature. $\mathrm{JJ}$ collected and analysed data. S and ZN writing manuscript.

\section{REFERENCES}

Almetwally, A. A, El-Sakhawy, M., Elshakankery, M. H.., \& Kasem, M. H. (2017) Technology of nano-fibers: Production techniques and properties Critical review. Journal of the Textile Association. 78(1):5-14.

An, T., Pant, B., Yun, S., Park, M., Park, S., \& Kim, H. (2017). Mechanical and optical properties of electrospun nylon-6, 6 nano fiber reinforced cyclic butylene terephthalate composites. Journal of Industrial and Engineering Chemistry. https://doi.org/10.1016/j.jiec.2017.06.04 4

Aruan, N. M., Sriyanti, I., Edikresnha, D., Suciati, T., Munir, M. M., \& Khairurrijal, K. (2017). Polyvinyl alcohol/soursop leaves extract composite nanofibers synthesized using electrospinning technique and their potential as antibacterial wound dressing. Procedia Engineering, 170, 31-35.

https://doi.org/10.1016/j.proeng.2017.03 .006

Bunaciu, A. A., Hoang, V. D., \& AboulEnein, H. Y. (2015). Applications of FTIR spectrophotometry in cancer diagnostics. Critical Reviews in Analytical Chemistry, 45(2), 156-165. https://doi.org/10.1080/10408347.2014. 904733.

Clasen, C., Bico, J., Entov, V. M., \& McKinley. (2009). Gobbling drops: the jetting-dripping transition inflows of polymer solutions. Journal of Fluid Mechanics, vol. 636, pp. 5-40, 2009. http://doi.org/10.1017/S0022112009008

\section{3}

Dai, X. Y., Nie, W., Wang, Y. C., Shen, Y., Li, Y., \& Gan, S. J. (2012). Electrospun emodin polyvinylpyrrolidone blended nanofibrous membrane: A novel medicated biomaterial for drug delivery and accelerated wound healing. Journal of Materials Science: Materials in Medicine, 23(11), 2709-2716. https://doi.org/10.1007/s10856-0124728-X

Edikresnha, D., Suciati, T., Munir, M.M., \& Khairurrijal, K. (2019). Polyvinylpyrrolidone/ celluloseacetate electrospun composite nanofibres loaded by glycerine andgarlic extract with in vitro antibacterial activity andrelease behaviour test. RSC Advances (2635126363). http://doi.org/10.1039/c9ra04072b

Gao, K., Shao, Z., Li, J., Wang, X., Peng, X., Wang, W., \& Wang, F. (2013). Cellulose nanofiber-graphene all solid-state flexible supercapacitors. Journal of Materials Chemistry A, 1(1), 63-67. https://doi.org/10.1039/c2ta00386d

Ismar, E., Karazehir, T., Ates, M., \& Sarac, A. S. (2018). Electrospun carbon nanofiber web electrode: Supercapacitor behavior in various electrolytes. Journal of Applied Polymer Science, 135(4), 1-10. https://doi.org/10.1002/app.45723

Jauhari, J., Wiranata, S., Rahma, A., Nawawi, Z \& Sriyanti, I. (2019). Polyvinylpyrrolidone/cellulose acetate nanofibers synthesized using electrospinning method and their characteristics. Materials Research Express, 6(6), 064002. https://doi.org/10.1088/2053-

1591/ab0b11

Kamaruddin, Sriyanti, I., Edikresnha, D., Munir, M. M., \& Khairurrijal, K. (2018). Electrosprayed polyvinylpyrrolidone (PVP) submicron particles loaded by green tea extracts. In IOP Conference Series: Materials Science and Engineering (Vol. 367). https://doi.org/10.1088/1757- 
899X/367/1/012036

Kang, E., Kim, M., Oh, J. S., Park, D. W., \& Shim, S. E. (2012). Electrospun BMIMPF 6/ nylon 6, 6 nanofiber chemiresistors as organic vapour sensors, 20(4), 372-378.

https://doi.org/10.1007/s13233-0120043-0

Kayaci, F., Ozgit-akgun, C., Donmez, I., Biyikli, N., \& Uyar, T. (2012). Polymer - Inorganic Core - Shell Nanofibers by Electrospinning and Atomic Layer Deposition: Flexible Nylon - ZnO Core - Shell Nanofiber Mats and Their Photocatalytic Activity. ACS Appl Mater Interfaces. 4(11):6185-94 https:// doi:10.1021/am3017976

Mehran, M., \& Mojtaba, N-E. (2011). HA/nylon 6,6 porous scaffolds fabricated by salt-leaching/solvent casting technique: effect of nano-sized filler content on scaffold properties. International Journal of Nanomedicine 2011:6 1651-1659. https://doi:10.2147/ijn.s21203

Matulevicius, J., Kliucininkas, L., Prasauskas, T., Buivydiene, D., \& Martuzevicius, D. (2016). The comparative study of aerosol filtration by electrospun polyamide, polyvinyl acetate, polyacrylonitrile and cellulose acetate nanofiber media. Journal of Aerosol Science, 92, 27-37. https://doi.org/10.1016/j.jaerosci.2015.1 0.006

Matabola, K. P., \& Moutloali, R.M. (2013). The influence of electrospinning parameters on the morphology and diameter of poly (vinyledene fluoride) nanofibers- effect of sodium chloride. Journal of Material Science. 48:54755482.

https://doi.org/s10853-013-7341-6

Opanasopit, P., Charernsriwilaiwat, N., \& Rojanarata, T. (2011). Electrospinning of chitosan based nanofiber mats as carriers for extract from the fruit hull of mangosteen, International Journal of Pharmacy. 16;452(1-2) http://doi:10.1016/j.ijpharm.2013.05.01
2.

Parlay, Ş., Avc, A., \& Pehlivan, E. (2019). Electrospinning of polymeric nanofiber (nylon 6, 6/ graphene oxide ) for removal of $\mathrm{Cr}$ (VI): synthesis and adsorption studies, Journal of Analytical Science and Technology 10:13. https://doi.org/10.1186/s40543-0190173-5.

Pillay, V., Dott, C., Yahya, E., Choonara, Tyagi, C., Tomar, L., Kumar, P., Lisa, C., Toit, D., \& Valence M. K. \& Ndesendo (2013). A review on polymer nanofibers by electrospinning and their applications in nanocomposites. Journal of Nanomaterials. https://doi.org/10.1155/2013/789289.

Ramakrishna, S., Fujihara, K., Teo, W. E., \& Lim, T.-C. (2005). An introduction to electrospinning and nanofibers. World Scientific.

Risdian, C., Nasir, M., Rahma, A., \& Rachmawati, H. (2015). The influence of formula and process on physical properties and the release profile of PVA/BSA nanofibers formed by electrospinning technique. Journal of Nano Research, 31, 103-116.

https://doi.org/10.4028/www.scientific.n et/JNanoR.31.103

Samprasit, W., Akkaramongkolporn, P., Ngawhirunpat, T., Rojanarata, T., Kaomongkolgit, R., \& Opanasopit, P. (2015). Fast releasing oral electrospun PVP/CD nanofiber mats of taste-masked meloxicam. International Journal of Pharmaceutics, 487(1-2), 213-222.

https://doi.org/10.1016/j.ijpharm.2015.0 4.044 05.03 .011

Shenoy, S. L., Bates, Wm. D., Frisch, H. L., \& Wnek, G. (2005). Role of chain entanglements on fiber formation during electrospinning of polymer solutions: Good solvent, non-specific polymerpolymer interaction limit. Polymer, 46(10), 3372-3348.

Shi, X., Zhou, W., Ma, D., Ma, Q., Bridges, D., Ma, Y., \& Hu, A. (2015). 
Electrospinning of nanofibers and their applications for energy devices.Journal of Nanomaterials. http://dx.doi.org/10.1155/2015/14071

Sriyanti, I., Edikresnha, D., Munir, M. M., Rachmawati, H., \& Rahma.A. (2016). Electrospun polyvinylpyrrolidone (PVP) nanofiber mats loaded by garcinia mangostana 1. extracts. Materials Science Forum (Vol. 880, pp. 11-14).

Sriyanti, I., Edikresnha, D., Rahma, A., Miftahul Munir, M., Rachmawati, H., \& Khairurrijal, K. (2018). Mangosteen pericarp extract embedded in electrospun PVP nanofiber mats: physicochemical properties and release mechanism of $\alpha$ mangostin. International Journal of Nanomedicine, Volume 13, 4927-4941. https://doi.org/10.2147/IJN.S167670

Sriyanti., I, Edikresnha., D., Rahma, A., Miftahul Munir, M., Rachmawati, H., \& Khairurrijal, K. (2017). Correlation between Structures and antioxidant activities of polyvinylpyrrolidone/garcinia mangostana 1. extract composite nanofiber mats prepared using electrospinning. Journal of
Nanomaterials. https://doi.org/10.1155/2017/9687896

Suwantong, O., \& Pankongadisak, P. (2014). Electrospun poly (L -lactic acid) fiber mats containing crude Garcinia mangostana extracts for use as wound dressings, PolymerBulletin 71, 925-949. https://doi.org/10.1007/s00289-0141102-9

Vongsetskul, T., Chantarodsakun, T., Wongsomboon, P., Rangkupan, R., \& Tangboriboonrat, P. (2015). Effect of solvent and processing parameters on electrospun polyvinylpyrrolidone ultrafine fibers. Chiang Mai Journal of Science, 42(2), 436-442.

Yu, Y., Ma R., Yana, S., \& Fan, J. (2018). Membranes by electrospinning and hot pressing. RSC Advances, 8, 12173 https://doi.org/10.1039/C8RA01442F

Yuxi Y, Rui, M., Shaole, Y., and Jiyu, F. (2018). Preparation of multi-layer nylon6 nanofibrous membranes by electrospinning and hot pressing methods for dye filtration: RSC Advances, 8, 12173. https://doi.org/10.1039/C8RA01442F 